\title{
Influence of Window-Wall ratio on global energy consumption of Nzeb kindergartens in Italy
}

\author{
Cecilia Ciacci ${ }^{1}$, Frida Bazzocchi ${ }^{1}$, Vincenzo Di Naso ${ }^{1}$, Andrea Rocchetti ${ }^{2}$ \\ ${ }^{1}$ University of Florence, School of Engineering, DICEA Department, Florence, Italy \\ ${ }^{21}$ University of Florence, School of Engineering, DIEF Department, Florence, Italy
}

\begin{abstract}
Window-wall ratio (WWR) is a parameter that necessarily affects the energy need for heating, cooling and lighting of buildings. Its definition during the early design process is remarkable to reduce the energy consumption. The aim of the paper is to optimize WWR minimizing global energy consumption in order to obtain Nzeb schools in mediterranean area. From the study it is possible to affirm that WWR exerts a considerable influence on energy consumption for heating and cooling, and to a lesser extent for lighting.
\end{abstract}

\section{Introduction}

\section{Background}

Window-wall ratio (WWR) is a parameter that necessarily affects energy need for heating, cooling and lighting of a building. Its definition during the early stage of design process is remarkable to minimize global energy consumption. Nevertheless it is important to consider that the glazed surface of a façade plays a primary role in the energy balance of a building for the exploitation of solar gains during the winter season (Goia, Haase, and Perino, 2013) and the consequent decrease in the energy demand for heating. Finally, to allow natural daylight to enter into indoor environments (Xue et al., 2019) and to create direct visual contact with the surrounding environments that promotes a feeling of well-being for the occupants of the building (Li 2010). The first studies about the influence of WWR with respect to the energy performance of buildings date back to the late 1970s (Arumi, 1977; Johnson et al., 1984) and they really concern the search of optimal window to wall ratio value for each orientation. The latest researches mainly concern office buildings (Marino, Nucara, and Pietrafesa, 2017; Feng et al., 2017; Alghoul, Rijabo, and Mashena, 2017; Goia, 2016; Wen, Hiyama, and Koganei, 2017) and WWR optimization for each orientation is achieved by minimizing energy consumption for heating, cooling and lighting (Goia, Haase, and Perino, 2013; Goia, 2016). Goia et al. (2016) define a range of optimal values of WWR through the application of a sensitivity analysis by varying building compactness, building equipment and artificial light efficiency. Wen et al. (2017) analyse this parameter with respect to $\mathrm{CO}_{2}$ reduction in the athmosphere (Wen, Hiyama, and Koganei, 2017). Some authors study this parameter considering the same building in many areas with different climate characteristics (Marino, Nucara, and Pietrafesa, 2017; Kheiri, 2013). The study of window to wall ratio is analysed compared to several other buildings distiguishing some features: façade insulation thickness (Johnson et al., 1984) or properties of glass (Lee et al., 2013; Grynning et al., 2013) compared to energy consumption for heating. Lee et al. (2013) study the relation between WWR the visible transmission and solar transmission of glass establishing an optimal range to minimize energy needs. Finally, Grynning et al. (2013) carry out a parametric analysis for an office building with three different methods considering the value of windows thermal transmittance and using glass solar factor.

\section{Aim of the research}

Nearly zero energy building (NZEB) school realisation cannot ignore the study of window sizing and distribution in façades not only to minimize global energy consumption but also because the light plays a key role in schools. According to the needs of new didactic methods visual contact with nature and direct connection of sections and collective areas with the surrounding environment are fundamental. Consequently, the study of window to wall ratio of a school building is also essential to provide well-being, comfort and good learning to students that spend most of their time in educational building. Schools are defined as complex buildings but italian standards and laws do not help for the definition of quantitative and qualitative design features (for instance geometry, dimensions, orientation and dimension of functional bands, WWR, active and/or passive energy and environmental strategies). The last national law concerning schools dates back to 1975 and essentially it deals with dimensional and distributive aspects without taking into account any aspects related to energy saving. In fact in Italy in 2016 only $0.3 \%$ of schools were energy efficiency label A (Report Legambiente Onlus, 2017).

The main aim of the study in the paper is the definition of the WWR influence for new typological models for kindergarten in terms of sustainabiliy and in order to obtain NZEB school buildings in Italy. The study proposed is a part of a broader work aimed at defining quantitative and qualitative guidelines as a supportive tool for designers in an early stage of the design process in order to realize NZEB schools in Mediterranean area.

Reasearch aims at studying different considered parameters to realize NZEB school buildings and at defining typological models optimised with respect to each climate zone. The first step of the research was to 
define new typological models, not available in literature, deduced from the analysis of a large number of contemporary case studies characterized by high energy efficiency. The present stage of the research concerns the optimization, considering different italian climate zones, of many design parameters. For instance, distribution and dimension of functional bands and units (Ciacci, 2018), choice of the best technological solution for external envelope in terms of dispersions, consumption and $\mathrm{CO}_{2}$ emissions, of insulation material and its thickness for both façade and roof and solar protections to be adopted for different orientations.

\section{Methods}

To evaluate the influence of WWR on global energy consumption for different identified models, a parametric analysis was carried out considering as a minimum value that one defined by current health-hygiene standars in Italy and as a maximum that one that can be achieved within the functional unit setting and as a limit for height the one corresponding to suspended ceiling inside rooms.

The analysis was carried out considering 5 cities belonging to different italian climate zones (D.P.R. 26 August 1993, n.412) and evaluating WWR for each orientation for three different typological models for kindergartens (Ciacci, 2018). The parametric analysis was performed by varying WWR for each orientation at a time keeping the remaining fixed to the minimum required by regulations. The only orientation where WWR was always maintained according to minimum regulatory requirement is the northen façade to avoid an increase of dispersion and consequently an increase in the energy consumption for heating. Indeed, in rooms facing like this, secondary functions are designed with limited dimensions and often without continuous presence of people and so they have lower visual comfort requirements. For each one of the three analysed typological models and in each orientation 4 different configuration of WWR were defined and analysed:

$\begin{array}{ll}- \text { model I1: } & \text { south }(25 \%-33 \%-50 \%-76 \%) \\ & \begin{array}{l}\text { east }(7 \%-17 \%-29 \%-36 \%) \\ \text { - mest }(7 \%-17 \%-23 \%-29 \%)\end{array} \\ & \text { south }(19 \%-33 \%-50 \%-76 \%) \\ & \text { east }(7 \%-17 \%-30 \%) \\ & \text { west }(8 \%-17 \%-30 \%-60 \%) \\ \text { - model I3: } & \text { south }(20 \%-34 \%-51 \%-77 \%) \\ & \text { west }(15 \%-33 \% 50 \%-77 \%)\end{array}$

This parametric analysis allow to identify the optimal solution for WWR for each basic models and in each orientation. In this context WWR refers to the ratio of glazed surface to the whole façade surface in each considered orientation. First of all, energy consumption for heating, cooling and lighting was evaluated separately. Thereafter, the optimal solution was found for each typological model and for each climate zone corresponding to that one that minimizes global energy consumption. It means the sum of required energy for heating, cooling, lighting, auxiliary system and service hot water considering systems performance. It is essential to point out that only the top three parameters are affected by WWR variation. For completness, the study of daylighting for classrooms (UNI 10840, 2007) in terms of daylighting factor and illuminance uniformity with respect to the optimal WWR was carried out in order to verify visual comfort (Jorge S. C., 2018). The study presented in this paper was conducted for 5 different cities but considering one of the three analysed models because the shape of classrooms is similar for all analysed models.

To be thorough, following parametric analysis a study was carried out to asses whether the WWR optimal solution for the city of Florence (climate zone D) (D.P.R. 26 August 1993, n.412) entailed an increase in thickness of façade insulation or a change in the type of glass with respect to the one used for the basic model. For this analysis the medium thermal transmittance of the elements of the envelope was calculated according to the Institute for Innovation and Transparency of Contracts and Environmental Compatibility (ITACA) for schools (ITACA Protocol for schools, 2011).

Finally for climate zone B (D.P.R. 26 August 1993, n.412), referring to the city of Palermo, a parametric analysis of properties of the used glass was performed, considering minimum WWR in the basic model. Properties taken into account are visible transmission $\left(\mathrm{T}_{\mathrm{vis}}\right)$ and solar transmission $\left(\mathrm{T}_{\mathrm{sol}}\right)$ of the outer pane of double-glazing unit. Type of glass was chosen from available templates in Design Builder (Tindale, 2005). This study aims at understanding how the variation of optical and energy characteristics of glass affects energy consumption of heating, cooling and lighting.

Obviously, the results of simulation of three basic models' simulation are strictly linked to both functional bands and units distribution, orientation, intended use and occupancy level.

\section{Models and basic input data}

\section{Climate zones}

An analysis for WWR optimization was carried out considering 5 different cities (table 1) belonging to 4 different climate zones in line with the national law D.P.R. 412/1993 (D.P.R. 26 August 1993, n.412) according to the number of heating degree days (HDD). Table 1 shows the following characteristics: altitude alt, latitude lat, longitude long, heating degree days HDD and Köppen Geiger climate classification K-G.

Tabella 1: characterization of 5 different Italian cities

\begin{tabular}{|c|c|c|c|c|c|}
\hline City & alt & lat & long & HDD & K-G \\
\hline Milan & 122 & $45.62^{\circ}$ & $8.73^{\circ}$ & 2404 & $\mathrm{Cfb}$ \\
\hline Florence & 50 & $41.8^{\circ}$ & $12.23^{\circ}$ & 1415 & $\mathrm{Cfb}$ \\
\hline Rome & 38 & $43.8^{\circ}$ & $11.2^{\circ}$ & 1821 & $\mathrm{Csa}$ \\
\hline Naples & 72 & $40.85^{\circ}$ & $14.3^{\circ}$ & 1034 & Csa \\
\hline Palermo & 34 & $38.18^{\circ}$ & $13.1^{\circ}$ & 751 & Csa \\
\hline
\end{tabular}

Energy simulations were performed with Energy Plus and climate data for typical year were used. They are calculated by the Italian Technical Commitee (CTI) based on the European standard EN ISO 15927-4 (EN ISO 15927-4, 2005). 


\section{Basic models}

For the study three typological basic models for kindergartens have been considered, previously outlined by the research (Ciacci, 2018): one with compact shape with 3 sections (Figure 1 - model I1) and with predominant linear shape with 3 and 6 sections respectively (Figure 2 model I 2 and Figure 3 model I3). All the models are designed with a distribution on a single ground floor.
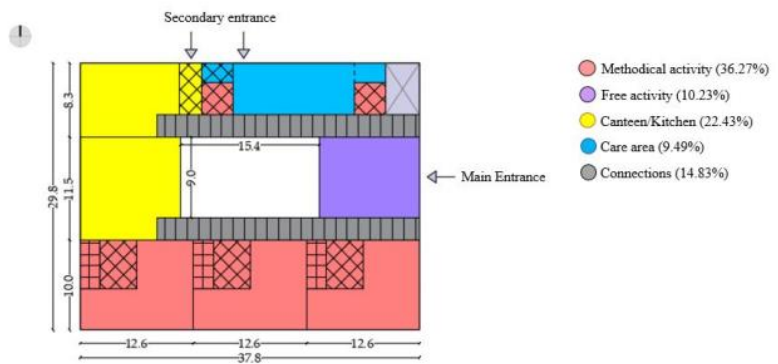
Free activity $(10.23 \%)$ Canteen Kitchen (22.43\%) Care area $(9.49 \%)$ Connections (14.83\%)

Figure 1: Typological model II

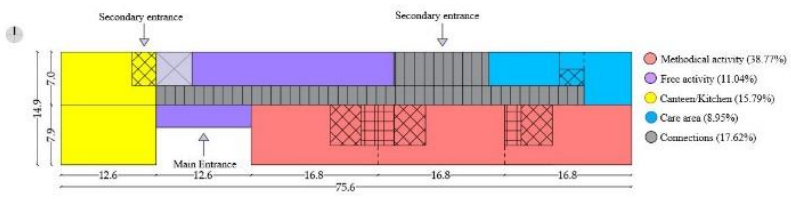

Figure 2: Typological model I2

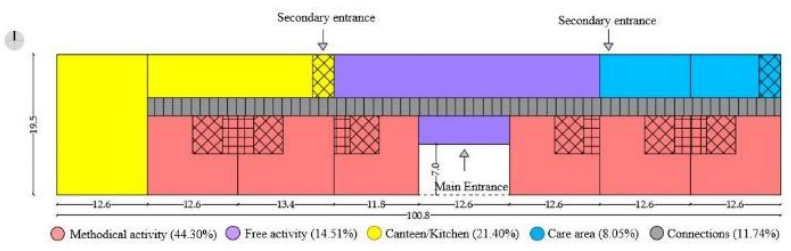

Figure 3: Typological model 13

Table 2 illustrates the main geometrical characteristics (volume $\mathrm{V}$, area $\mathrm{S}$, length $\mathrm{A}$, width $\mathrm{B}$, internal height $\mathrm{H}$ ) of the models.

Table 2: geometrical characteristics of kindergarten basic models

\begin{tabular}{|c|c|c|c|c|c|}
\hline Model & $\mathbf{V}\left[\mathbf{m}^{\mathbf{3}}\right]$ & $\mathbf{S}\left[\mathbf{m}^{\mathbf{2}}\right]$ & $\mathbf{A}[\mathbf{m}]$ & $\mathbf{B}[\mathbf{m}]$ & $\mathbf{H}[\mathbf{m}]$ \\
\hline I1 & 5154.6 & 888.7 & 37.8 & 29.8 & 4.4 \\
\hline I2 & 5534.8 & 954.3 & 75.6 & 14.9 & 4.4 \\
\hline I3 & 10764.8 & 1736.3 & 100.8 & 19.5 & 4.8 \\
\hline
\end{tabular}

The construction method with cross laminated timber (XLAM) was used for both external envelope and roof floor. This solution was applied because it is one of the most recurrent for the realization of kindergartens in the Mediterranean area. Table 3 indicates the main characteristics of materials that are adopted for the layers of the external envelope while table 4 shows those for ventilated roof. In both tables thickness of insulation required to comply with medium thermal transmittance of the envelope elements has been identified according to Italian law limit (D.M. 26 June 2015) in different climate zones.

Table 3: External envelope layers

\begin{tabular}{|c|c|c|c|}
\hline Layer & Material & $\mathbf{t}[\mathbf{m}]$ & $\boldsymbol{\lambda}[\mathbf{W} / \mathbf{m K}]$ \\
\hline 1 & External plaster & 0.025 & 0.9 \\
\hline
\end{tabular}

\begin{tabular}{|c|c|c|c|}
\hline 2.1 & Wood fiber B & 0.04 & 0.038 \\
\hline 2.2 & Wood fiber C & 0.10 & 0.038 \\
\hline 2.3 & Wood fiber D & 0.14 & 0.038 \\
\hline 2.4 & Wood fiber E & 0.14 & 0.038 \\
\hline 3 & XLAM & 0.13 & 0.12 \\
\hline 4 & Gypsum board & 0.015 & 0.21 \\
\hline
\end{tabular}

Table 4: Roof floor layers

\begin{tabular}{|c|c|c|c|}
\hline Layer & Material & $\mathbf{t}[\mathbf{m}]$ & $\boldsymbol{\lambda}\left[\mathbf{W} / \mathbf{m}^{\mathbf{2}} \mathbf{K}\right]$ \\
\hline 1 & Metal sheet & 0.0005 & 1.07 \\
\hline 2 & Air cavity & 0.05 & - \\
\hline 3 & Waterproof sheet & 0.004 & 0.2 \\
\hline 4.1 & Wood fiber B & 0.18 & 0.038 \\
\hline 4.2 & Wood fiber C & 0.18 & 0.038 \\
\hline 4.3 & Wood fiber D & 0.22 & 0.038 \\
\hline 4.4 & Wood fiber E & 0.24 & 0.038 \\
\hline 5 & Vapour barrier & 0.0003 & 0.17 \\
\hline 6 & XLAM & 0.125 & 0.12 \\
\hline
\end{tabular}

For ground floor layers the solution with plastic formwork for underfloor ventilation was completed with expanded polystirene (EPS) insulation layer. Finally, related to windows, a thermal break frame was adopted $\left(\mathrm{U}_{\mathrm{f}}=1.7\right.$ $\mathrm{W} / \mathrm{m}^{2} \mathrm{~K}$ ) and a double glazing with different properties was used to comply with thermal transmittance required by D.M. 26 June 2015 (D.M. 26 June 2015) according to climate zone (Table 5).

Table 5: Glass characteristics with respect to climate zone

\begin{tabular}{|c|c|c|c|}
\hline $\begin{array}{c}\text { Climate } \\
\text { zone }\end{array}$ & $\begin{array}{c}\mathbf{U g} \\
{\left[\mathbf{W} / \mathbf{m}^{\mathbf{2}} \mathbf{K}\right]}\end{array}$ & $\begin{array}{c}\text { Solar } \\
\text { factor [\%] }\end{array}$ & $\begin{array}{c}\text { Light } \\
\text { transmittance } \\
{[\%]}\end{array}$ \\
\hline B & 2.5 & 69 & 78 \\
\hline C-D & 1.2 & 50 & 74 \\
\hline E & 1.1 & 52 & 75 \\
\hline
\end{tabular}

For instance, regarding climate zone D, applying materials with such characteristics and adopting glass with mentioned properties, the medium thermal transmittance of the envelope elements is equal to 0.231 $\mathrm{W} / \mathrm{m}^{2} \mathrm{~K}$.

On southern façade of each models a fixed shading system has been designed and realized with an overhang of 2.00 $\mathrm{m}$ against each windows in façade. This type of solar protection was used because it ensures a total shading for glazed elements during the summer season. Furthermore, it allows kids to have a constant visual contact with sorrounding nature. No shading system has been adopted on eastern and western façade because for models with this kind of functional distribution, the inclusion of solar shading system on those orientations does not lead to a benefit in terms of energy consumption $(<1 \%)$. For those orientations only in the functional units of the classrooms there are not windows.

\section{Design Builder setup}

Energy simulations in dynamic condition with hourly time step of configured buildings were carried out through Energy Plus software using Design Builder as the graphical interface. For each different thermal zone, in which buildings have been divided, many parameters were defined: occupancy (person $/ \mathrm{m}^{2}$ ) according to UNI 
10339 (June 1995 - Appendix A), minimum air change rate refers to the same legislation (June 2015 - Table 3) and finally internal gains in line with UNI/TS 11300-1 (October 2014 - Table 17). Concerning level of illuminance UNI EN 12464-1 (June 2011) was considered. Regarding simulations, lighting control was used with the maximum index of glare allowed.

Systems are simulated through HVAC simple and main design parameters are shown below:

- controlled mechanical ventilation (VMC): free cooling and sensible heat recovery with $50 \%$ of efficiency;

- heating/cooling system: gas boiler with efficiency equal to 0.9, chiller with $\mathrm{EER}=2.5$;

- heating setpoint: $20^{\circ} \mathrm{C}$ activity period $-10^{\circ} \mathrm{C}$ during the rest of the day;

- cooling setpoint: $26^{\circ} \mathrm{C}$ activity period $-36^{\circ} \mathrm{C}$ during the rest of the day;

- auxiliary energy: $6 \mathrm{kWh} / \mathrm{m}^{2}$;

- service hot water: gas boiler with efficiency equal to 0.9 with hot water outlet temperature equal to $65^{\circ} \mathrm{C}$.

\section{Results and Discussion}

In the following section the main results of the parametric analysis are reported and discussed. The parametric analysis was performed for 3 new typological models for kindergartens. Figure 4 and Figure 5 shows the relationship between WWR variation on southern oriented façade and energy consumption respectively for heating and cooling for each climate zone considered for model I1 characterized by compact shape with internal courtyard.

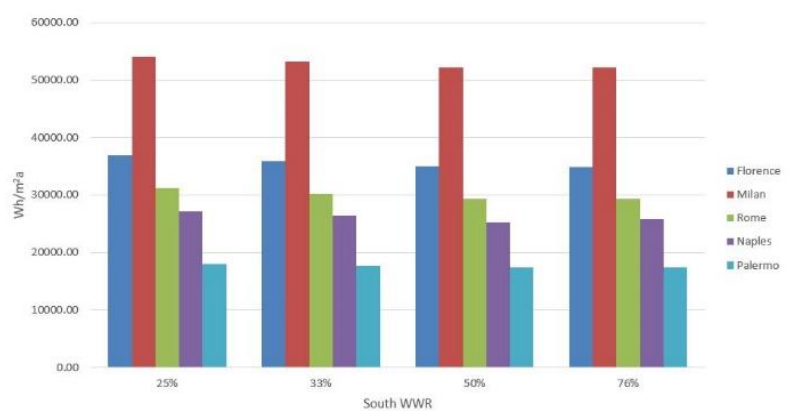

Figure 4: Heating consumption with respect to south WWR variation model II

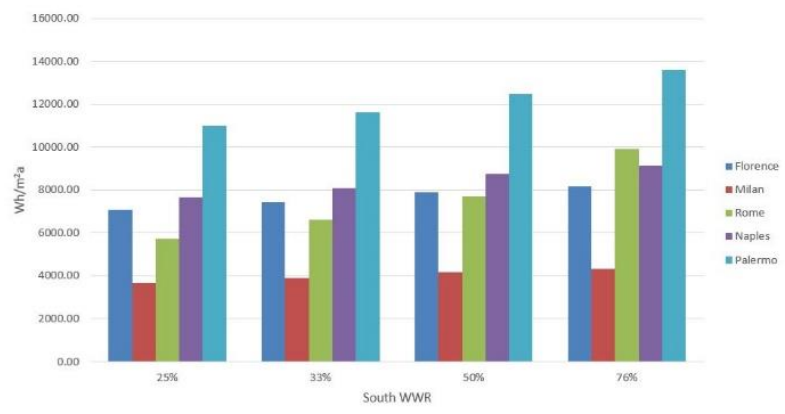

Figure 5: Cooling consumption with respect to south WWR variation model II
From Figure 4 it is possible to notice that for Milan, Florence and Rome (climate zones E and D) the energy variation required for heating from WWR value equal to $25 \%$ to $50 \%$ is remarkable because it leads to a decrease in energy consumption of about $1700 \mathrm{Wh} / \mathrm{m}^{2} \mathrm{a}$. However, the difference in terms of energy consumption for the winter season is basically irrelevant (about $60 \mathrm{Wh} / \mathrm{m}^{2} \mathrm{a}$ ). For Naples and Palermo (climate zones C and B) with a milder climate and the summer season with higher temperatures the most appreciable variation relates to energy for cooling that increases considerably with south WWR increase as shown in Figure 5. This also occurs with the overhang of $2.00 \mathrm{~m}$ on southern façade because for the autumn and spring season it does not ensure the total shading of glazed elements (for example for the month of September). Furthermore, the type of glass used for Palermo is definitely characterized by a low energy performance compared to that one applyed to the other climate zones because for B climate zone the law requires a less restrictive value of thermal transmittance.

For models I 2 and I3 the development of variation of energy consumption for heating is the same as model I1. As far as cooling is concerned, the increase of energy consumption with the increase of WWR for Naples and Palermo cities is significant as shown in Figure 6.

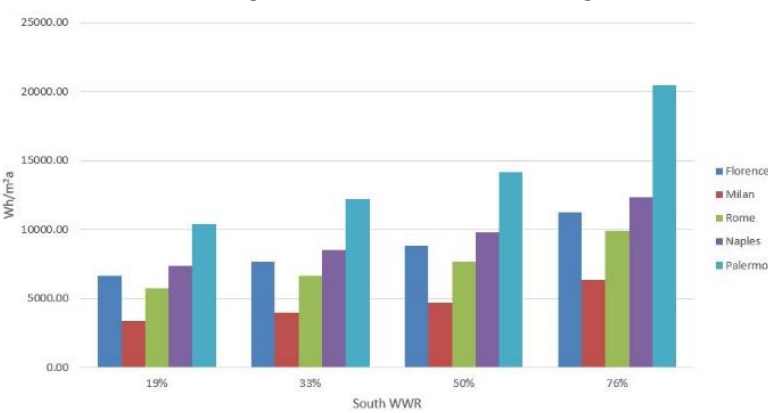

Figure 6: Cooling consumption with respect to south WWR variation model $I 2$

Especially for the model with 3 classrooms (I2) for Naples there is an increase of $12400 \mathrm{Wh} / \mathrm{m}^{2} \mathrm{a}$ of energy required for cooling compared to the basic model with WWR equal to $76 \%$ while for Palermo of $25100 \mathrm{Wh} / \mathrm{m}^{2} \mathrm{a}$. It is possible to state that the increase of WWR for south orientation does not lead to a benefit in terms of energy consumption in every climate zone, particularly for those zones that have higher temperatures during the summer season. Therefore, it is essential to carefully analyse the energy performance of buildings also during the summer season in order to avoid unreasonably overheated rooms and consequently an oversize air conditioning system. This consideration is linked to the concept of modern school that has become a real civic centre that is used by residents during extracurricular time and by students and teachers for extracurricular activities even during the summer season.

Figure 7 and Figure 8 depict the relationship between WWR variation on eastern oriented façade and energy consumption respectively for heating and cooling for 
model I1 characterized by compact shape with internal courtyard (I1).

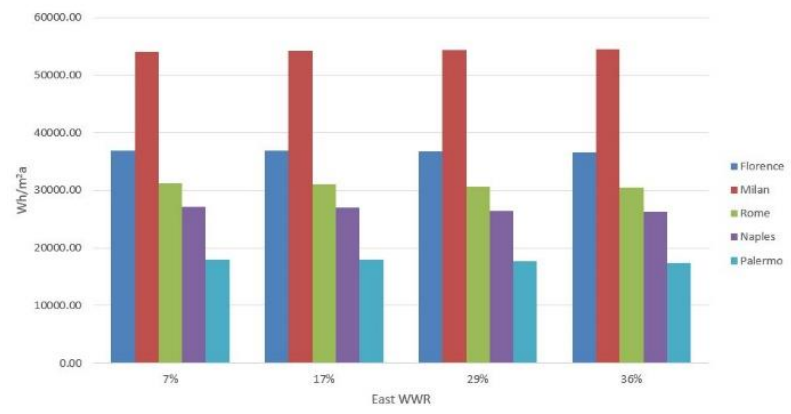

Figure 7: Heating consumption with respect to east WWR variation model II

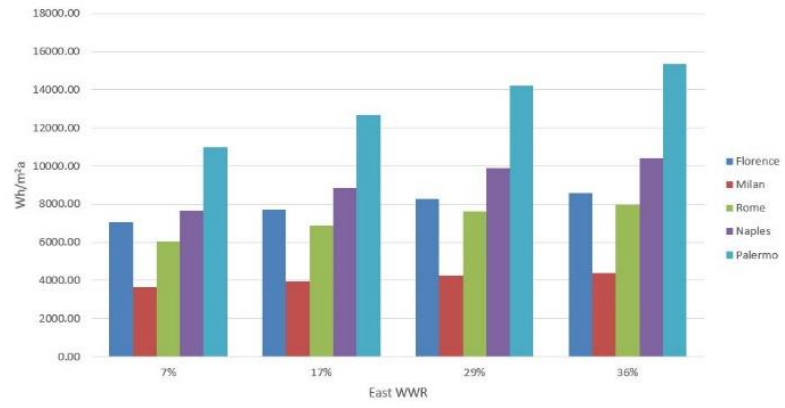

Figure 8: Cooling consumption with respect to east WWR variation model II

Figure 9 and Figure 10 illustrate the energy consumption for heating and cooling regarding WWR variation for west façade.

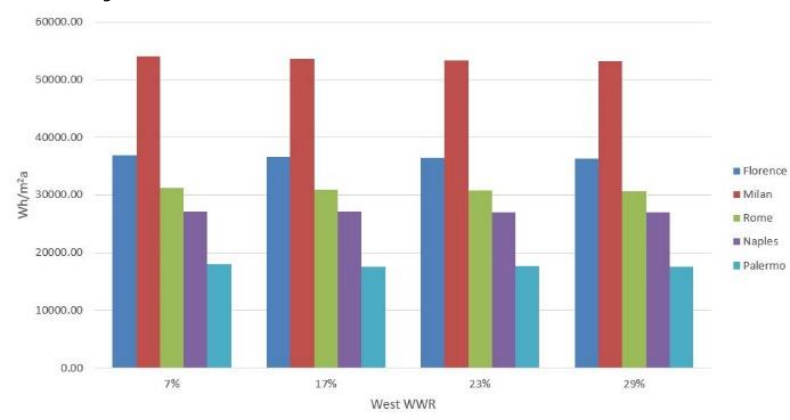

Figure 9: Heating consumption with respect to west WWR variation model II

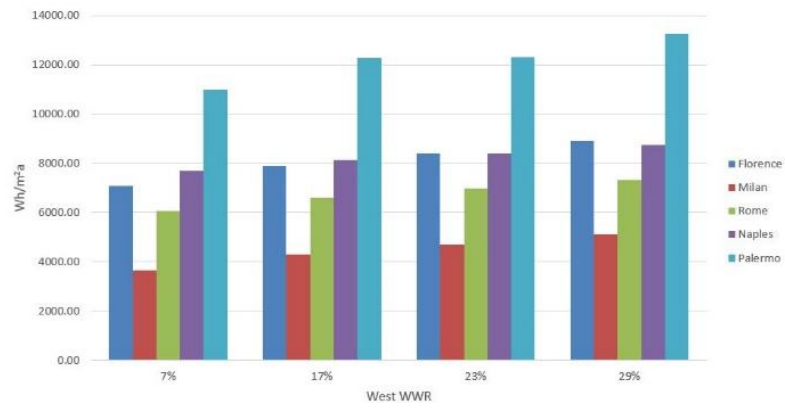

Figure 10: Cooling consumption with respect to west WWR variation model II

Graphs analysis allows to assert that for this school model with compact shape with internal courtyard (I1) the WWR variation on eastern and western orientation is practically irrelevant with regard to energy consumption for heating. While for what concerns cooling it is necesary to discuss results considering different climate zones. For Milan, Florence and Rome with the highest WWR available (36\% east or $29 \%$ west) there is not a noticeable increase of cooling energy need. However, for Naples and Palermo, an increase of WWR on eastern façade leads to a more relevant rise in energy consumption for the summer season with respect to western façade. This increase of consumption can be compared with that one on southern façade and it occurs on the same scale. Consequently, it is possible to state that the increase of WWR on eastern façade mainly affects global energy consumption with respect to the same increase on western façade for a building with compact shape, distingueshed by this orientation of functional bands and by this distribution of internal functional units (Figure 1) characterized by particular occupancy and air change rate.

Talking about the other two models I 2 and I 3 the increase of WWR on eastern and western façade affects global energy consumption of building to a definitly lesser extent compared to that one on the southern façade. This is mainly linked to the shape of basic models that have a more predominant linear shape with one dimension than the other one with a prevailing axis along east-west direction. Finally WWR influences to a lesser extent lighting energy consumption. In fact for each model and for each climate zone there is not a significant decrease of lighting consumption. The increase of southern WWR is still the most influential with regard to this parameter.

It is important to point out that in schools, due to the typical high crowding of the intended use of this buidling, the contribution of ventilation exerts a considerable influence on energy balance and consequently on global energy consumption. Necessarily, the presented results are significantly influenced by the high ventilation required for air change rate to comply with regulations especially for classrooms and the canteen.

As already described in the methodology, the optimal solution for WWR for each typological model is that one that minimizes the energy consumption. Consequently, window to wall ratio for each orientation has been optimized for each model and every climate zone. In the following section the results related to the city of Florence with respect to model I1 are presented (Figures 11-12). For $\mathrm{E}$ and $\mathrm{D}$ climate zones and for each typological model the lowest energy consumption is obtained by having on southern façade WWR equal to $50 \%$ and keeping WWR of other façades to the minimum level. In such climate zones, this is due to the fact that the highest energy consumption for school building occurs during winter season. However, as shown in Figure 13, for what concerns Palermo and so for Naples, cooling gives the most significant contribution in terms of energy during the summer season. Then, the optimal solution is that one with the minimum WWR in each orientation and for each typological model. The graph related to west orientation was omitted because it is like east one. The search of WWR optimal solution in complex building cannot ignore internal functional distribution and site geographic 
location. An improper design of WWR of a building during the preliminary phase of the design process involves both an oversizing of a system and an increase of energy needs of the building.

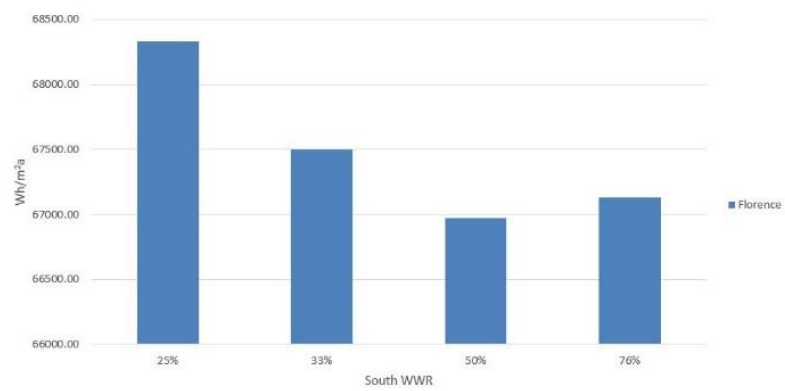

Figure 11: Optimization of WWR in Florence and for South orientation model II

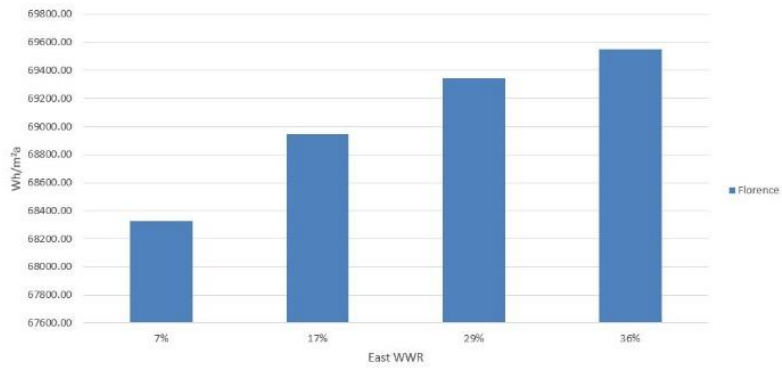

Figure 12: Optimization of WWR for Florence for east orientation model II

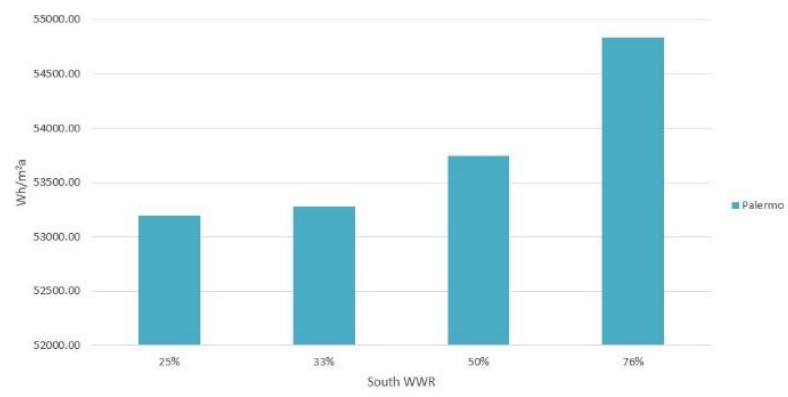

Figure 13: Optimization of WWR for Palermo for south orientation for model II

The value of WWR for each orientation has been analysed also with respect to the medium thermal transmittance of the elements of the envelope. For instance, table 6 illustrates results related to the compact shape with an internal courtyard (model I1) for the city of Florence (climate zone D). Once the optimal WWR for each orientations has been defined according to previous considerations, the variation of the medium thermal transmittance was evaluated by varying WWR for south orientation only. As maximum reference limit, the value of the medium thermal transmittance was considered equal to $0.324 \mathrm{~W} / \mathrm{m}^{2} \mathrm{~K}$ for climate zone $\mathrm{D}$, assessed in according to ITACA protocol for schools. For that assessment, thermal transmittance of external envelope was considered equal to $0.199 \mathrm{~W} / \mathrm{m}^{2} \mathrm{~K}$ and that one for windows varied according to the glass surface and the frame surface ratio, remaining however equal to about $1.48 \mathrm{~W} / \mathrm{m}^{2} \mathrm{~K}$. Thermal transmittance of roof floor is equal to $0.130 \mathrm{~W} / \mathrm{m}^{2} \mathrm{~K}$ while that one for ground floor is equal to $0.25 \mathrm{~W} / \mathrm{m}^{2} \mathrm{~K}$.

Table 6: Global envelope transmittance in relation to south WWR variation

\begin{tabular}{|c|c|c|c|c|}
\hline WWR & $\begin{array}{c}\mathbf{A}_{\text {wa }} \\
{\left[\mathbf{m}^{\mathbf{2}}\right]}\end{array}$ & $\begin{array}{c}\mathbf{A}_{\text {wi }} \\
{\left[\mathbf{m}^{\mathbf{2}}\right]}\end{array}$ & $\begin{array}{c}\mathbf{U}_{\text {se }} \\
{\left[\mathbf{W} / \mathbf{m}^{2} \mathbf{K}\right]}\end{array}$ & $\begin{array}{c}\mathbf{U}_{\mathbf{m}} \\
{\left[\mathbf{W} / \mathbf{m}^{\mathbf{2}} \mathbf{K}\right]}\end{array}$ \\
\hline $25 \%$ & 174.84 & 44.4 & 0.46 & 0.231 \\
\hline $33 \%$ & 146.04 & 73.20 & 0.63 & 0.243 \\
\hline $50 \%$ & 109.44 & 109.80 & 0.85 & 0.258 \\
\hline $76 \%$ & 52.92 & 166.32 & 1.18 & 0.282 \\
\hline
\end{tabular}

Table 6 (Wall area $A_{w a}$, window area $A_{w i}$, south envelope transmittance $U_{\text {se }}$, mean thermal transmittance of envelope elements $U_{m}$ ) shows that for the optimal WWR (figures 10-11-12) of model with the compact shape (I1) and for the climate characteristics of the city of Florence there is a significant increase in the medium thermal transmittance of the external wall due to the increase in the glass surface with respect to the basic model. However, it minimally affects the medium thermal transmittance of the elements of the envelope that remains under the value of $0.3 \mathrm{~W} / \mathrm{m}^{2} \mathrm{~K}$. According to this result it is possible to point out that for this model it is not necessary either to increase the thickness of insulation or to change the type of the basic glass used.

Moreover, in order to examine the visual comfort for south orientated classrooms with respect to the optimal WWR a daylighting analysis was performed. With the aim of avoid glare a solar protection with horizontal blinds with high reflectivity slats were considered with automated control on glare (maximum glare index 21) (UNI 10840, 2007). For Milan, Florence and Rome a south WWR equal to $50 \%$ was considered with 2 windows for each class, while for Naples and Palermo a minimum WWR with only one window for each class to guarantee the minimum average daylighting factor required by regulation. The analysis was carried out considering 2 different dates: the 21 st of June and the $21 \mathrm{st}$ of December both at $12 \mathrm{pm}$. Table 7 shows the results of this study in terms of average daylighting factor $\left(\eta_{\mathrm{m}}\right)$ and daylighting uniformity $\left(\eta_{\min } / \eta_{\mathrm{m}}\right)$ for 3 different classes of model I1 considering the entire area and not only with respect the real position of visual tasks.

Table 7: Average DF and UE for classrooms in different cities

\begin{tabular}{|c|c|c|c|c|c|}
\hline \multirow[t]{2}{*}{ City } & \multirow[t]{2}{*}{ Class } & \multicolumn{2}{|c|}{$\begin{array}{c}\eta_{m} \\
{[\%]}\end{array}$} & \multicolumn{2}{|c|}{$\begin{array}{c}\boldsymbol{\eta}_{\mathrm{m}} \text { Uniformity } \\
\left(\boldsymbol{\eta}_{\min } / \boldsymbol{\eta}_{\mathrm{m}}\right)\end{array}$} \\
\hline & & 21.06 & 21.12 & 21.06 & 21.12 \\
\hline \multirow[t]{3}{*}{ Milan } & 1 & 14.60 & 20.30 & 0.20 & 0.10 \\
\hline & 2 & 14.10 & 19.80 & 0.18 & 0.09 \\
\hline & 3 & 13.70 & 19.70 & 0.17 & 0.09 \\
\hline \multirow[t]{3}{*}{ Florence } & 1 & 14.50 & 20.40 & 0.20 & 0.09 \\
\hline & 2 & 13.90 & 19.80 & 0.16 & 0.08 \\
\hline & 3 & 13.77 & 19.90 & 0.18 & 0.085 \\
\hline \multirow[t]{3}{*}{ Rome } & 1 & 14.30 & 20.30 & 0.21 & 0.10 \\
\hline & 2 & 13.40 & 19.80 & 0.18 & 0.09 \\
\hline & 3 & 13.30 & 19.70 & 0.18 & 0.09 \\
\hline \multirow[t]{3}{*}{ Naples } & 1 & 5.70 & 7.90 & 0.14 & 0.04 \\
\hline & 2 & 5.40 & 7.70 & 0.12 & 0.05 \\
\hline & 3 & 5.40 & 7.75 & 0.12 & 0.05 \\
\hline Palermo & 1 & 5.70 & 8.50 & 0.15 & 0.06 \\
\hline
\end{tabular}




\begin{tabular}{|l|l|l|l|l|l|}
\hline & 2 & 5.50 & 8.30 & 0.11 & 0.07 \\
\hline & 3 & 5.30 & 8.20 & 0.12 & 0.06 \\
\hline
\end{tabular}

With respect to daylighting analysis related to the optimum WWR the minimum $\eta_{\mathrm{m}}$ is in according to current italian regulation. Instead, especially for winter season, the average values for light uniformity suggest that it is necessary to turn on artifical light particularly due to the use of automated internal solar protection for the glare. But it is important to point out that lighting maps show that the lower value of daylighting factor was obviously found in the farthest area from the window where the resting area is organised.

Finally, the last considerations concern the variation of the properties of the external pan of double-glazing windows for Palermo, located in climate zone B. This study has been conducted because this city is characterized by a climate characterised by 5 months with temperature above $20^{\circ} \mathrm{C}$ during the summer season. Under such conditions, glass properties and its dimension significantly affect the energy performance of buildings, energy needs for cooling and nonetheless well-being of the occupants. Table 7 indicates the main characteristics of the different types of external pans used to performed simulations. The transmittance value is not indicated because it is the same as the basic solution (Table 5) in order to avoid its influence on the results of the analysis. The model (I1) with a compact shape with an internal courtyard is analysed.

Table 7: Main characteristics of different type of glass (AGC manufacturer)

\begin{tabular}{|c|c|c|c|}
\hline Name of glass & Type & $\begin{array}{c}\text { Ts } \\
{[\%]}\end{array}$ & Tv [\%] \\
\hline Stratobel & 55.1 & 0.713 & 0.868 \\
\hline Stratobel & 66.1 & 0.685 & 0.858 \\
\hline Stratobel & 66.2 & 0.673 & 0.858 \\
\hline Clearvision & 12 & 0.879 & 0.908 \\
\hline Solarshield green & 6 & 0.37 & 0.704 \\
\hline Krystal clear & 12.AFG & 0.881 & 0.908 \\
\hline Defender Ti-R & 090.AFG & 0.406 & 0.704 \\
\hline Defender embedded & DefCS73 & 0.573 & 0.807 \\
\hline Defender comfort E72 & DrClrE2 & 0.611 & 0.831 \\
\hline Comfort select73 & CS73Lami & 0.586 & 0.812 \\
\hline Flatglass Philippines & FL6.AFP & 0.785 & 0.882 \\
\hline ASAHI GLASS & FL5.AGC & 0.829 & 0.895 \\
\hline
\end{tabular}

Figure 14 shows the energy consumption for heating, cooling and lighting with respect to different types of external pans of double-glazing windows for Palermo.

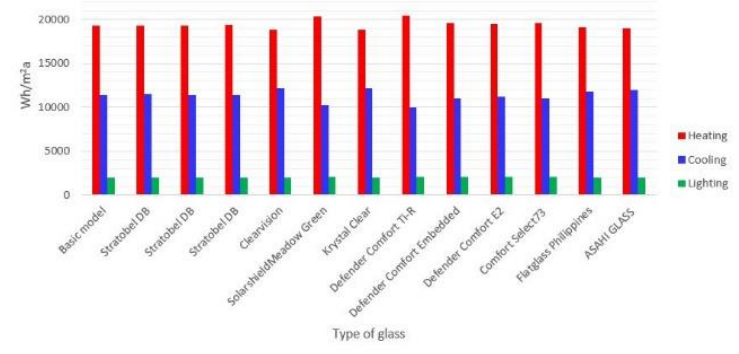

Figure 14: Heating, cooling and lighting consumption in relation to different type of glass
Figure 14 shows that visible transmittance and solar transmittance affect energy needs of buildings compared to the basic solution in the case of optimal solution for WWR for Palermo. This applies especially for energy consumption for cooling. This solution allows to have a benefit of about $1500 \mathrm{Wh} / \mathrm{m}^{2}$ a for cooling and it is the one that adopts Defender Comfort Ti-R as external pane. It is characterised by a value of solar transmittance approximately equal to half of that of the basic solution. Concerning energy consumption for lighting the optimal solution is that one characterised by a high visible transmission and a low solar transmission. The best solution is the use of a Clearvision pane. However, cooling requirement for Palermo affected more significantly the energy consumption than the lighting one. Consequently, in both this situations and with regard to WWR, the optimal solution is certainly the one that minimizes cooling needs.

\section{Conclusion}

The performed simulations point out that WWR exerts a considerable influence on the global energy consumption even for a building school designed on a single ground floor, that has a high performance envelope and a high air change rate for ventilation. As shown by the study window to wall ratio cannot ignore the identification of the climate zone where a building is located, the shape and finally the orientation and the distribution of functional bands and units. Regarding colder climate zones, the increase in WWR positively affects the energy needs for heating that decreases when the south oriented glazed surface increases (Milan - WWR 76\% - decrease of 5\%). While, for those zones, WWR does not affect cooling consumption considerably. For the cities of Napoli and Palermo, that are characterized by a milder climate with higher temperatures during the year, the cooling needs increases substantially with an increase in the south WWR (Naples - WWR 76\% - increase of 18.8\%; Palermo - WWR 76\% - increase of $23.5 \%$ ). This condition is particularly accentuated in model I 2 and I 3 defined by a predominat linear shape with a prevailing axis along eastwest direction. The analysis of the variation on east and west façade allows to stress that south orientation is not the only critical one, especially for the typological model with a compact shape and for milder climates. Increasing WWR mainly for east orientation leads to a noticeable increase of energy needs for cooling. It occurs at the same scale and in the conditions of south orientation. This situation changes for models with a predominant linear shape that presents limited dimensions along east and west directions. The carried out simulations, for different typological models in 5 different cities already discussed in the paper, confirm that the study of the proper WWR during the preliminary phase of the design process leads to a noticeable decrease in terms of energy consumption even for a single store building.

\section{References}

Alghoul S. K., Rijabo H.G. and Mashena M. E. (2017). Energy Consumption in Buildings: A Correlation for the Influence of Window to Wall Ratio and Window 
Orientation in Tripoli, Libya. Journal of Building Engineering 11(April), 82-86.

Arumi, F. (1977). Day Lighting as a Factor in Optimizing the Energy Performance of Buildings. Energy and Buildings 1 (2), 175-82.

Ciacci, C. (2018). Progettazione di scuole NZEB: nuovi modelli tipologici per la scuola dell'infanzia e la scuola primaria in Italia. Conference paper Colloquiate 2018: Edilizia circolare tra recupero/riqualificazione e rinnovo/rigenerazione urbana e architettonica. Cagliari (ITA), 12-14 September 2018.

Decreto del Presidente della repubblica (1993). Regolamento Recante Norme per la progettazione, l'installazione, l'esercizio e la Manutenzione degli Impianti Termici degli Edifici ai fini del contenimento dei consumi di energia. (D.P.R. 26 August 1993, n.412).

Ente nazionale italiano di unificazione (2007). Locali scolastici. Criteri generali per l'illuminazione naturale ed artificiale (UNI 10840).

Ente nazionale italiano di unificazione (2004). Illuminazione dei posti di lavoro -- Parte 1 (UNI EN 12464-1).

Ente nazionale italiano di unificazione (2005). Impianti aeraulici a fini di benessere generalità, classificazione e requisiti regole per la richiesta d'offerta, l'offerta, l'ordine e la fornitura (UNI 10339: 2005).

Ente nazionale italiano di unificazione (2014). Prestazioni energetiche degli edifici -- Parte 1: Determinazione del fabbisogno di energia termica dell'edificio per la climatizzazione estiva ed invernale (UNI/TS 11300-1)

Feng G., Chi D., Xu X., Dou B., Sun Y. and Fu Y. (2017). Study on the Influence of Window-Wall Ratio on the Energy Consumption of Nearly Zero Energy Buildings. Procedia Engineering 205, 730-37.

Goia, F. (2016). Search for the Optimal Window-to-Wall Ratio in Office Buildings in Different European Climates and the Implications on Total Energy Saving Potential. Solar Energy 132, 467-92.

Goia, F., Haasse M., and Perino M. (2013). Optimizing the Configuration of a Façade Module for Office Buildings by Means of Integrated Thermal and Lighting Simulations in a Total Energy Perspective. Applied Energy 108, 515-27.

Governo Italiano (2015). Applicazione delle metodologie di calcolo delle prestazioni energetiche e definizione delle prescrizioni e dei requisiti minimi degli edifici. (15A05198), GU Serie Generale n. 162 del 15-n. 7-n. 2015-n." Suppl. Ord., 26 (D.M. 26 June 2015).

Grynning, S., Gustavsen A., Time B. and Jelle B. P. (2013). Windows in the Buildings of Tomorrow: Energy Losers or Energy Gainers? Energy and
Buildings 61, 185-92.

International organisation of Standardisation (2005). Hygrothermal Performance of Buildings -Calculation and Presentation of Climatic Data -- Part 4: Hourly Data for Assessing the Annual Energy Use for Heating and Cooling (ISO EN 15927-4)

Institute for Innovation and Transparency of Contracts and Environmental Compatibility (2011). ITACA Protocol for schools.

Johnson, R., Sullivan R., Selkowitz S., Nozaki, S., Conner C., and Arasteh D. (1984). Glazing Energy Performance and Design Optimization with Daylighting. Energy and Buildings 6 (4), 305-17.

Jorge S., C. (2018).Optimal window geometry factors for elementary school buildings in Portugal. Journal of Green Building, 185-97.

Kheiri, F. (2013). The Relation of Orientation and Dimencional Specification of Window with Building Energy Consumption in Four Different Climates of Koppen Classification Researcher 5 (12), 107-15.

Lee, J. W., H. J. Jung, J. Y. Park, J. B. Lee, and Yoon Y. (2013). Optimization of Building Window System in Asian Regions by Analyzing Solar Heat Gain and Daylighting Elements. Renewable Energy 50, 522-31.

Legambiente Onlus (2017). Ecosistema Scuola XVIII. Rapporto Di Legambiente Sulla Qualità Dell'edilizia Scolastica, Delle Strutture e Dei Servizi

Li D. H. W. (2010). A Review Od Daylight Illuminance Determinations and Energy Implications. Applied Energy 87, 2109-18.

Marino C., A. Nucara, and Pietrafesa M. (2017). Does Window-to-Wall Ratio Have a Significant Effect on the Energy Consumption of Buildings? A Parametric Analysis in Italian Climate Conditions. Journal of Building Engineering 13(August), 169-83.

Tindale, A. (2005). Designbuilder Software Ltd.

Wen L., Kyosuke H. and Makoto K. (2017). A Method for Creating Maps of Recommended Window-to-Wall Ratios to Assign Appropriate Default Values in Design Performance Modeling: A Case Study of a Typical Office Building in Japan. Energy and Buildings 145, 304-17.

Xue P., Li Q., Xie J., Zhao M. and Liu J. (2019). Optimization of Window-to-Wall Ratio with Sunshades in China Low Latitude Region Considering Daylighting and Energy Saving Requirements. Applied Energy 233-234 (100), 62-70. 